\title{
Preparation and Electrocatalytic Hydrogen Evolution properties of Lignin-derived Cabon/Ni/NiO Composites
}

\author{
Shiyi Jiang ${ }^{1}$, Xuan $\mathrm{Yu}^{1}$, Leiting Han ${ }^{1}$, Dan Qiao ${ }^{1}$, Zhengping Zhao ${ }^{1, *}$, Jiahao Wang $^{2}$, \\ Mingqiang Zhong ${ }^{2}$ \\ ${ }^{1}$ Zhijiang College, Zhejiang University of Technology, Hangzhou 310014, P.R. China \\ ${ }^{2}$ College of Materials Science and Engineering, Zhejiang University of Technology, Hangzhou \\ 310014, P. R. China \\ "E-mail: sjzhaolei@163.com
}

Received: 3 June 2021 / Accepted: 26 July 2021 / Published: 10 September 2021

\begin{abstract}
In recent decades, the lignin has been numerously abandoned in agricultural and paper industries, which is urging us to find the new usage of it. And in theory, lignin is a kind of available material as carbon source because of its low cost, wide distribution and abundant carbon content. Therefore, researchers intend to make it a flesh porous carbon as new energy material. In this paper, lignin-derived porous carbon was prepared by self-assembly method and combined with $\mathrm{Ni} / \mathrm{NiO}$. Then the nanocomposites' structure and hydrogen evolution reaction were studied. The main research contents and results were as follows: $\mathrm{Ni} / \mathrm{NiO}$ and lignin-drived porous carbon were combined by in-situ synthesis, and the morphology, composition, structure, and electrochemical performance were characterized. It was found that $\mathrm{Ni}$ and $\mathrm{NiO}$ were indeed absorbed on porous carbon as crystals. The composite's specific surface area measured by BET was $115.4 \mathrm{~m}^{2} \cdot \mathrm{g}^{-1}$, while pore volume is $0.04 \mathrm{~cm}^{3} \cdot \mathrm{g}^{-1}$. And hydrogen evolution hyperpotential of the composite electrode is $0.446 \mathrm{~V}$ at $10 \mathrm{~mA}$.
\end{abstract}

Keywords: lignin; mesoporous carbon; composite electrode; hydrogen evolution reaction

\section{$\underline{\text { FULL TEXT }}$}

(C) 2021 The Authors. Published by ESG (www.electrochemsci.org). This article is an open access article distributed under the terms and conditions of the Creative Commons Attribution license (http://creativecommons.org/licenses/by/4.0/). 